\title{
Kemicond-käsitellyn puhdistamolietteen käyttö viherpeitteisen kaatopaikan katemateriaalina
}

\author{
Tapio Salo ja Petri Kapuinen \\ Maa- ja elintarviketalouden tutkimuskeskus, Kasvintuotannon tutkimus, Maaperä ja ympäristö, 31600 \\ Jokioinen, tapio.salo@mtt.fi
}

\section{Tiivistelmä}

Käsittelemätöntä puhdistamolietettä ei saa enää uuden lannoitevalmistelain ja -asetuksen voimaan tultua käyttää edes viherrakentamisessa. Sitä voidaan laillisesti luovuttaa vain sijoitettavaksi ympäristölainsäädännön nojalla hyväksytylle kaatopaikalle tai poltettavaksi hyväksytyssä polttolaitoksessa. Jotta puhdistamolietettä voidaan käyttää maanparannusaineena tai kasvualustan raakaaineena, se on käsiteltävä esimerkiksi Kemicond-menetelmällä. Siinä esikuivattu puhdistamoliete hygienisoidaan ennen lopullista kuivaamista lisäämällä siihen rikkihappoa ja vetyperoksidia.

Lannoitevalmisteasetus säätelee myös lannoitevalmistelain mukaan hyväksytyssä laitoksessa käsitellyn lannoitevalmisteen käyttömääriä viherrakentamisessa sekä maa- ja metsätaloudessa. Maataloudessa käytettäviä typpimääriä säätelee lisäksi ns. nitraattiasetus. Maatalouden käyttömääriä säätelee käytännössä kuitenkin maatalouden ympäristötukijärjestelmä, koska lähes kaikki maatilat kuuluvat järjestelmän piiriin ja sen asettamat rajoitukset ovat lainsäädännön rajoituksia tiukemmat. Kaatopaikkojen katemateriaalina ja maisemoinnissa sekä viherrakentamisessa lietteitä voi käyttää tätä enemmän. Maisemointiin sisältyy yleensä vaatimus kasvillisuuden perustamisesta kaatopaikalle. Vihreän kasvuston perustaminen olisi helppoa, jos liete katettaisiin riittävällä kerroksella varta vasten valmistettua kasvualustaa tai sellaista seostettaisiin riittävä määrä lietteeseen. Tällainen kasvualusta on kuitenkin kallista, ja kustannusten säästämiseksi sen käyttö haluttaisiin minimoida.

Tutkimuksen tavoitteena oli selvittää, miten varta vasten valmistetun kasvualustan käyttö voidaan minimoida lietteellä maisemoidun kaatopaikan katteessa, johon halutaan viherpeite.

Astiakokeessa tutkittiin raiheinän kasvualustana käsittelemättömiä ja Kemicond-käsiteltyjä lietteitä, niiden seoksia ruokamullan tai kasvuturpeen kanssa sekä ruokamullalla tai kasvuturpeella katettuja Kemicond-käsiteltyjä lietteitä. Verranteena ja lietteisiin sekoitettavina kasvualustoina käytettiin ruokamultaa (hieno hieta) ja lannoittamatonta kasvuturvetta. Kate- ja verrannekäytössä ne lannoitettiin Viherympäristöliiton suositusten mukaisesti. Koeastiat sijoitettiin kasvihuoneeseen ja kasteltiin 1,5 kk:n kasvatuksen kuluessa sopivasti. Kasvualustoista mitattiin happamuutta, johtokykyä kasvualustasta ja valumavedestä sekä ravinne- ja haitallisten metallien pitoisuuksia. Kasvustosta mitattiin sen korkeus ja sato.

Kaikki lietteet sellaisenaan olivat liian väkeviä kasvualustaksi. Kompostoidussa Kemicondlietteessä oli havaittavissa pientä taimettumista ja kasvua, mutta kasvu oli selvästi heikompaa kuin ruokamullassa. 20 til.-\% ruokamultaa tai kasvuturvetta ei riittänyt laimentamaan lietettä niin, että raiheinä olisi siinä taimettunut ja kasvanut kompostoitua Kemicond-lietettä lukuun ottamatta. Viiden senttimetrin paksuinen ruokamulta tai turvekerros katteena lietteiden päällä edisti raiheinän kasvua, mutta vain kompostoitu Kemicond-liete katettuna ruokamullalla tuotti yhtä hyvän kasvun kuin ruokamulta. Jos kaatopaikan tai vastaavan maisemointiin käytetty Kemicond-liete halutaan viherpeitteiseksi, sitä on syytä ensin kompostoida noin vuosi, sitten kattaa ruokamullalla ja kylvää heinäkasvien siemenillä. Kokeissa käytetyn 1-vuotisen raiheinän sijasta käytännön toiminnassa on tarkoituksenmukaisinta käyttää jotain monivuotista heinäkasvia, jonka kasvustoa ei tarvitse perustaa joka vuosi uudelleen. Monivuotisilla nurmikasveilla kasvutulosten voidaan olettaa olevan samanlaiset kuin yksivuotisella raiheinälläkin.

Asiasanat: Kemicond-menetelmä, puhdistamoliete, viherpeite, kaatopaikka, maisemointi, katemateriaali, kasvualusta, johtokyky, ravinteet, haitalliset metallit 


\section{Johdanto}

Käsittelemätöntä puhdistamolietettä ei saa enää uuden lannoitevalmistelain (Eduskunta 2006) ja asetuksen (MMM 2007) voimaan tultua käyttää edes viherrakentamisessa. Sitä voidaan laillisesti luovuttaa sijoitettavaksi vain ympäristölainsäädännön nojalla hyväksytylle kaatopaikalle tai poltettavaksi hyväksytyssä polttolaitoksessa. Tämä lainsäädäntö säätelee varsin tiukasti myös lannoitevalmistelain (Eduskunta 2006) mukaan hyväksytyssä laitoksessa käsitellyn lannoitevalmisteen käyttömääriä viherrakentamisessa sekä maa- ja metsätaloudessa. Maataloudessa käytettäviä typpimääriä säätelee lisäksi ns. nitraattiasetus (VN 2000). Maatalouden käyttömääriä säätelee käytännössä kuitenkin maatalouden ympäristötukijärjestelmä (VN 2007), koska lähes kaikki maatilat kuuluvat järjestelmän piiriin ja sen asettamat rajoitukset ovat lainsäädännön rajoituksia tiukemmat. Kaatopaikkojen katemateriaalina ja maisemoinnissa lietteitä voi käyttää tätä enemmän. Toivottavaa olisi kuitenkin, että näin maisemoidulla kaatopaikalla kasvaisi jotain vihreää. Vihreän kasvuston perustaminen olisi helppoa, jos liete katettaisiin riittävällä kerroksella varta vasten valmistettua kasvualustaa tai sellaista seostettaisiin riittävä määrä lietteeseen. Tällainen kasvualusta on kuitenkin kallista, ja kustannusten säästämiseksi sen käyttö haluttaisiin minimoida. Tutkimuksen tavoitteena oli selvittää, miten valmistetun kasvualustan käyttö voidaan minimoida lietteellä maisemoidun kaatopaikan katteessa, johon halutaan viherpeite.

\section{Aineisto ja menetelmät}

Astiakokeessa tutkittiin lietteiden ja ruokamullan tai kasvuturpeen seoksia raiheinän kasvualustana (Taulukko 1). Astiakoe perustettiin elokuun 2006 lopulla, ja raiheinän kasvua mitattiin lokakuuhun 2006 asti. Astiat sijoitettiin avoseinäiseen ja lasikattoiseen astiakoehalliin. Astioita kasteltiin päältä, ja astian läpi ala-astiaan valuvan veden määrä pyrittiin pitämään mahdollisimman pienenä. Verranteena ja lietteisiin sekoitettavina kasvualustoina käytettiin ruokamultaa (hieno hieta) ja lannoittamatonta kasvuturvetta. Astiakokeen perustamisen yhteydessä kasvualustojen raaka-aineista otettiin näytteet johtokyvyn, $\mathrm{pH}: \mathrm{n}$ ja ravinnepitoisuuksien määritystä varten.

Verrannekasvualustat eli pelkkää kasvuturvetta tai ruokamultaa sisältäneet kasvualustat ja verrannekasvualustamateriaaleista valmistetut $5 \mathrm{~cm}$ :n katekerrokset lannoitettiin Viherympäristöliiton nurmikon ravinnepitoisuussuositusten (VYL 2004) mukaisesti. Tavoitteena oli saada kasvualustan liukoisten ravinteiden pitoisuuksiksi N 50, P 13 ja K 50 mg/l. Lisäksi edellä mainituille käsittelyille annettiin hivenlannoitus. Lannoitus annettiin liuoksena, joka sekoitettiin koko lannoitettuun kasvualustaan (2 1:n astiat) tai katekerrokseen ( $5 \mathrm{~cm}: n$ katekerrokset). Kuhunkin astiaan kylvettiin raiheinää $300 \mathrm{mg}$ (noin $75 \mathrm{kpl} / \mathrm{astia}, 4000 \mathrm{kpl} / \mathrm{m}^{2}$ ja $16 \mathrm{~kg} / \mathrm{ha}$ ). Astiat siirrettiin astiakoehalliin 24.8.2006.

Astioita kasteltiin tarpeen mukaan, ja raiheinän orastumisesta tehtiin havaintoja. Kasvuston pituus mitattiin viivoittimen avulla 13.9.2006 eli noin kahden viikon kuluttua perustamisesta. Orastumattomista kasvualustoista otettiin 21.9.2006 näytteet, joista määritettiin kuivatun kasvualustanäytteen (1:5 vesiuutto) sekä valumaveden $\mathrm{pH}$ ja johtokyky. Kasvusto korjattiin 4.10.2006 ja kasvustonäytteet punnittiin tuoreena ja kuivattiin $60^{\circ} \mathrm{C}$ lämpötilassa $24 \mathrm{~h}$, jonka jälkeen punnittiin näytteiden kuivapaino.

Kasvualustojen raaka-aineista määritettiin viljavuusanalyysin mukaisesti johtokyky, $\mathrm{pH}$, fosfori, kalium ja kalsium (MTT 1986). Tuoreista näytteistä määritettiin epäorgaaninen typpi $2 \mathrm{M} \mathrm{KCl-uutolla} \mathrm{ja}$ pH sekä johtokyky lannoitevalmistelain (Eduskunta 2006) mukaisella 1:5 uuttosuhteella (CEN 1999a ja CEN 1999b).

Koejäsenistä, joissa oli kasvua, testattiin ensiksi yksisuuntaisen varianssianalyysin avulla kasvuston korkeudet, tuore- ja kuiva-ainesadot. Dunnettin testillä verrattiin muita käsittelyjä ruokamullan tuottamaan kasvuun. Sen jälkeen lieriöissä kasvatetut koejäsenet $(15-22)$ analysoitiin kaksisuuntaisella varianssianalyysilla faktorikokeena, jossa faktoreina olivat $5 \mathrm{~cm}: n$ katekerroksen tyyppi (multa tai turve) ja käytetyt lietteet (käsittelemätön kuivattu jätevesiliete, Porin kuivattu Kemicond-käsitelty liete, Uudenkaupungin Kemicond-käsitelty liete ja 11 kk kompostoitu Kemicond-käsitelty liete). Katekerroksen tai lietteiden välisiä eroja testattiin Tukey-Kramerin testillä. 


\section{Taulukko 1. Astiakokeen käsittelyt}

Verranteet kasvualustana

1. Pelkkä kasvuturve

2. Pelkkä ruokamulta

Puhdistamolietteet sellaisenaan kasvualustana

3. Käsittelemätön kuivattu jätevesiliete (Pori)

4. Kuivattu Kemicond-liete, Pori (PoriKC)

5. Kuivattu Kemicond-liete, Uusikaupunki (UgiKC)

6. 11 kk kompostoitu Kemicond-liete (KompKC)

Lietteet kasvualustana seostettuna turpeen kanssa (kokonaistilavuudesta $20 \%$ turvetta)

7. Käsittelemätön kuivattu jätevesiliete

8. Kuivattu Kemicond-liete, Pori

9. Kuivattu Kemicond-liete, Ugi

10. $11 \mathrm{kk}$ kompostoitu Kemicond liete

Lietteet kasvualustana seostettuna ruokamullan kanssa (kokonaistilavuudesta $20 \%$ ruokamultaa)

11. Käsittelemätön kuivattu jätevesiliete

12. Kuivattu Kemicond-liete, Pori

13. Kuivattu Kemicond-liete, Ugi

14. $11 \mathrm{kk}$ kompostoitu Kemicond-liete

$\sim 30 \mathrm{~cm}: n$ liete kasvualustana katettuna $5 \mathrm{~cm}: n$ turvekerroksella

15. Käsittelemätön kuivattu jätevesiliete

16. Kuivattu Kemicond-liete, Pori

17. Kuivattu Kemicond-liete, Ugi

18. $11 \mathrm{kk}$ kompostoitu Kemicond-liete

$\sim 30 \mathrm{~cm}: n$ liete kasvualustana katettuna $5 \mathrm{~cm}: n$ ruokamultakerroksella

19. Käsittelemätön kuivattu jätevesiliete

20. Kuivattu Kemicond-liete, Pori

21. Kuivattu Kemicond-liete, Ugi

22. $11 \mathrm{kk}$ kompostoitu Kemicond-liete

\section{Tulokset ja tulosten tarkastelu}

Keskeisin syy raiheinän orastumattomuuteen oli lietteiden selvästi liian suuri johtokyky. Lietteet olivat lähinnä lannoitteita eikä kasvualustoja, vaikka ne lannoitevalmisteasetuksessa (MMM 2007) orgaanisiksi maanparannusaineiksi luetaankin. Seostettujen kasvualustojen tilavuussuhteen 8:2 (Kemicond-liete: ruokamulta tai turve) olisi pitänyt olla pikemminkin päinvastainen, jotta raiheinän olisi voinut odottaa orastuvan.

Lietteiden johtokyky oli niille tyypillisen korkea 200 - $1000 \mathrm{mS} / \mathrm{m}$ (uuttosuhde 1:5) (Kuva 1). Kasvualustan johtokyvyksi suositellaan 30-60 mS/m (VYL 2004), ja yli $100 \mathrm{mS} / \mathrm{m}$ lukemat ovat kasvien kasvulle usein selvästi liian korkeat. Orastumattomista koeastioista 21.9. määritetyt johtokyvyt (kuivattu näyte, $1: 5$ uutto) olivat $500-2000 \mathrm{mS} / \mathrm{m}$, koska uuttosuhde oli perustamisvaiheen näytteitä pienempi kuiva-aineen määrään suhteutettuna. Orastumattomien astioiden läpi valuneen veden johtokyky oli myös korkea, 300-1800 mS/m. Kaikkien orastumattomien kasvualustojen $\mathrm{pH}$ oli kasvien kasvun kannalta sopivalla alueelle (pH 5,7-6,3). 


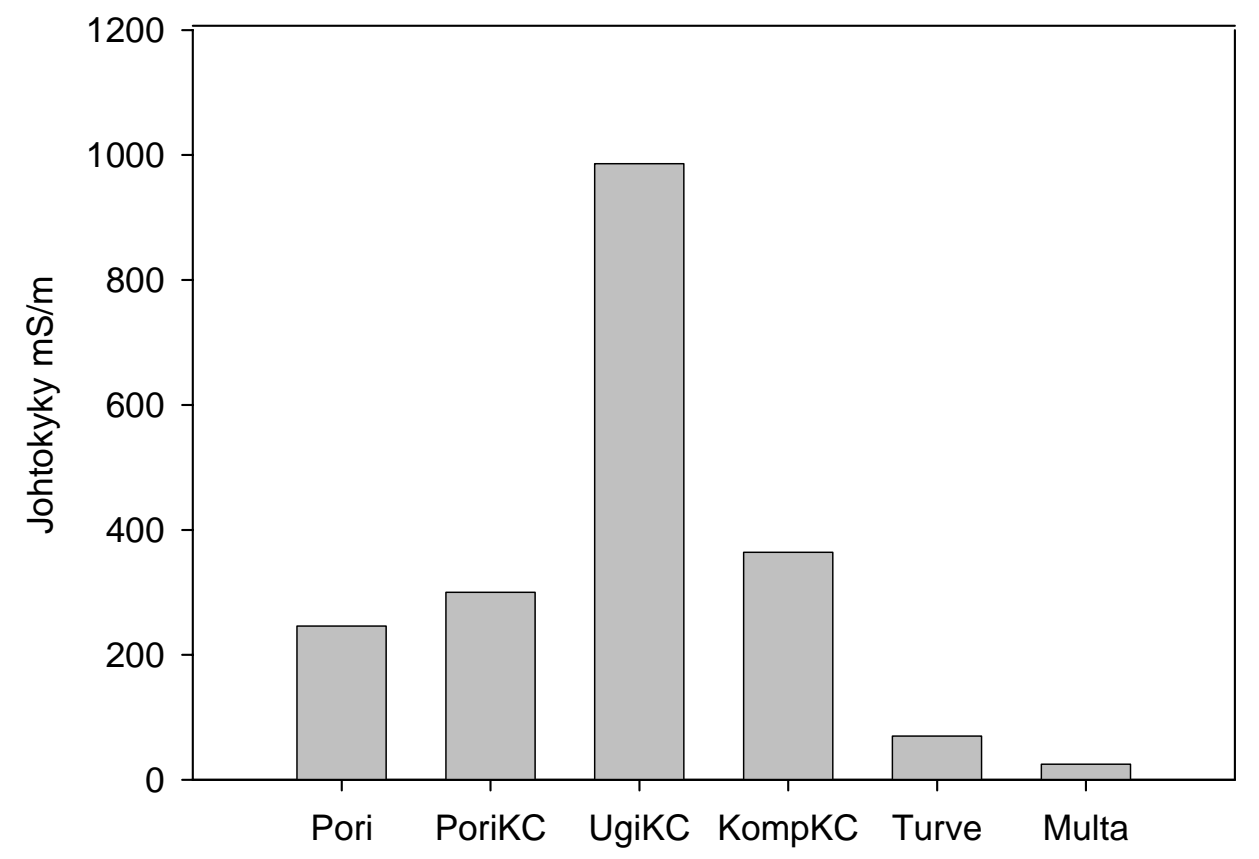

Kuva 1. Kasvualustojen raaka-aineiden (Taulukko 1) johtokyky kokeen alussa 1:5 vesiuutossa.

Astiakokeen perustamishetkellä lietteiden ammoniumtypen pitoisuudet olivat korkeita (Kuva 2). Nitraattityppeä lietteissä ei ollut. Kasveille käyttökelpoista fosforia ja kaliumia kuvaavan viljavuusuuton mukaan kasvualustojen fosfori- ja kaliumpitoisuudet (Kuva 3) olivat riittäviä kasvien kasvulle (Viljavuuspalvelu 2000).

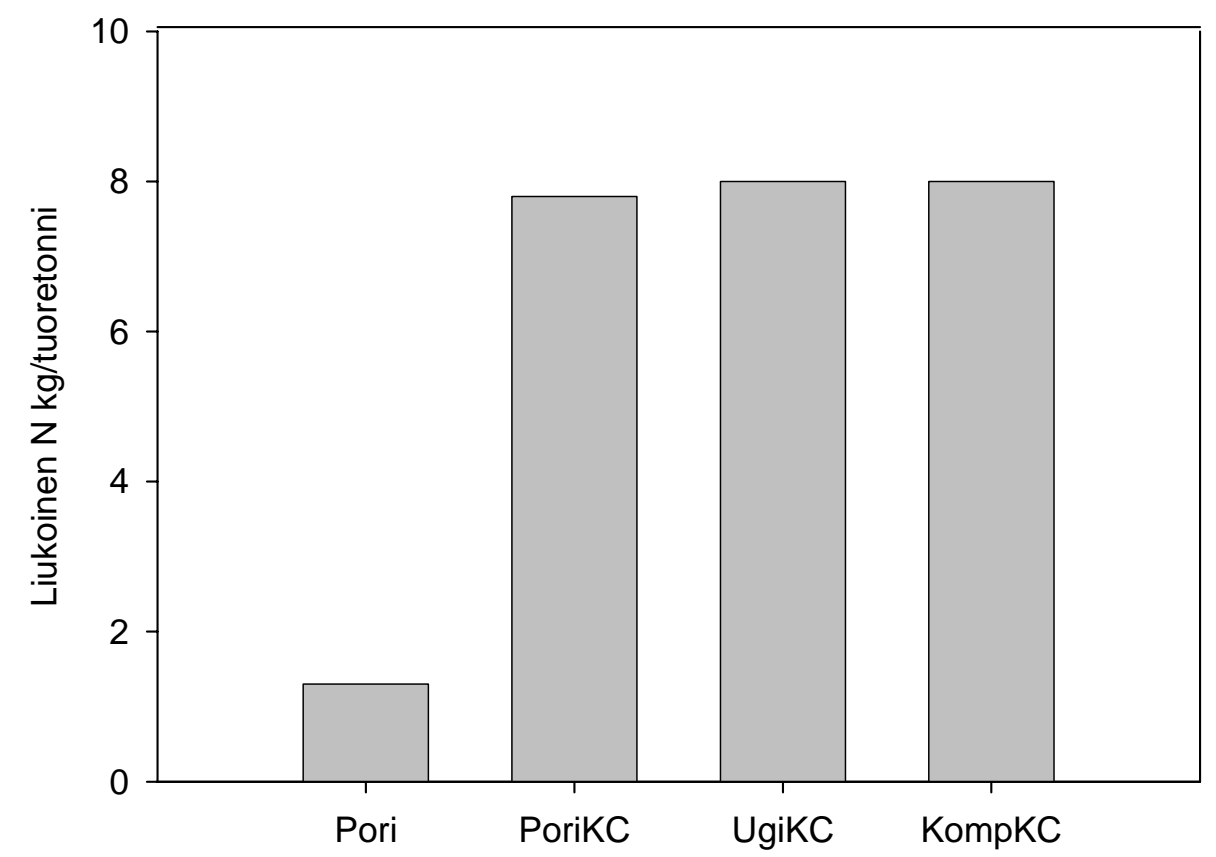

Kuva 2. Kasvualustan raaka-aineina käytettyjen lietteiden (Taulukko 1) ammoniumtypen määrät $2 \mathrm{M}$ kaliumkloridi-uutolla määritettynä. 


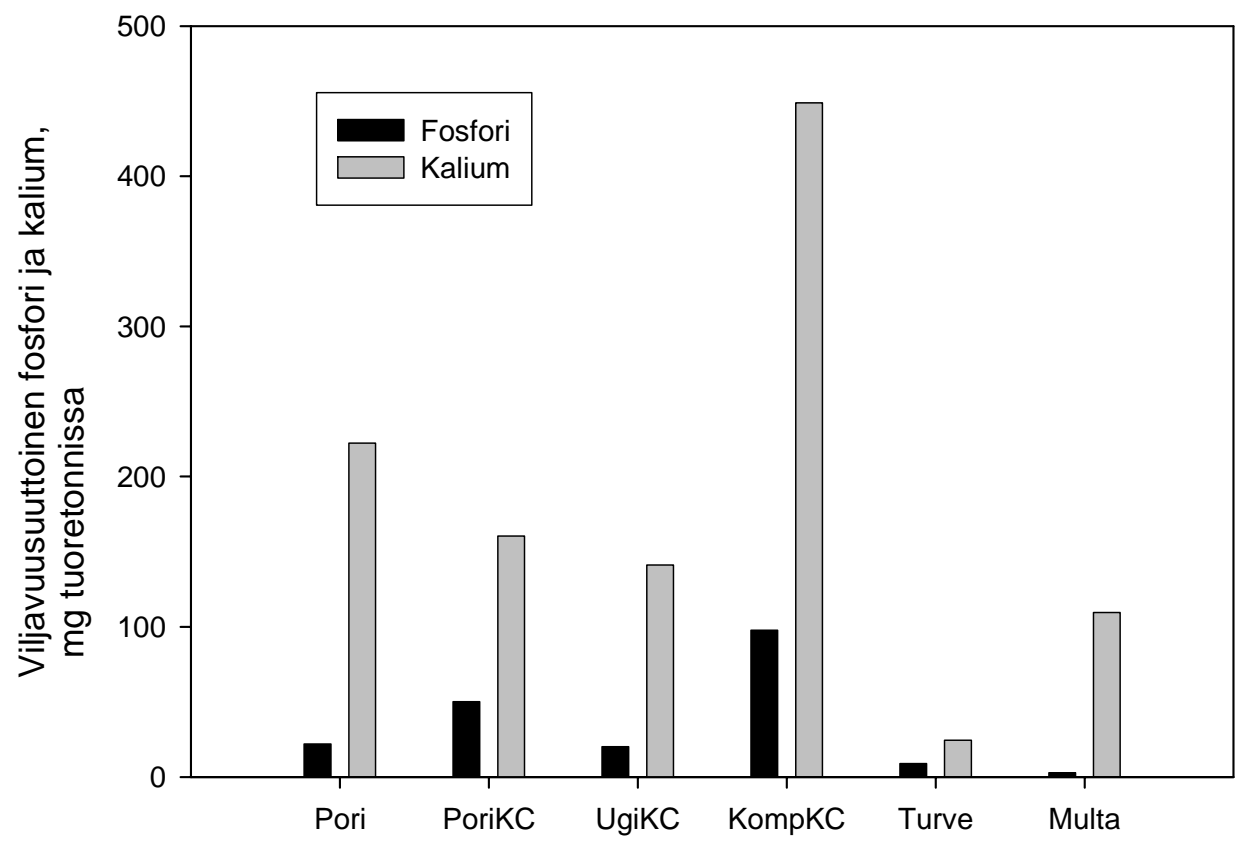

Kuva 3. Kasvualustan raaka-aineina käytettyjen lietteiden (Taulukko 1) fosfori- ja kaliumpitoisuudet viljavuuanalyysin (hapan ammoniumasetaattiuutto) mukaan.

Ensimmäisten kasvualustojen orastumiset havaittiin 30.8. eli kuuden päivän kuluttua kokeen perustamisesta. Nopeimmin raiheinä orastui verranteina olleissa ruokamullassa ja kasvuturpeessa sekä kaikissa $40 \mathrm{~cm}: n$ lieriöissä, joissa liete oli katettu $5 \mathrm{~cm}: n$ ruokamulta- tai kasvuturvekerroksella. Jonkin verran orastumista oli havaittavissa myös kompostoidussa Kemicond-lietteessä. Kompostoitu Kemicondliete oli ainoa liete, jossa taimettumista tapahtui sellaisenaan tai $20 \%$ turve- tai ruokamultalisäyksen kanssa.

Kasvusto oli korkein ruokamullan ollessa kasvualustana tai katekerroksena. Pelkässä kompostoimattomassa Kemicond-lietteessä raiheinä ei orastunut lainkaan. Kasvuston korkeus oli pienin, kun ruokamullalla katettu liete oli Uudenkaupungin Kemicond-käsiteltyä lietettä, koska sen johtokyky oli lietteiden johtokyvyistä suurin. Se, että turvekatteelliset kasvualustat orastuivat huonosti, aiheutui siitä, että turpeen $\mathrm{pH}$ oli liian matala, vaikka alla olevan lietteen $\mathrm{pH}$ olikin sopivalla alueella. Turvekatteellisten kasvualustojen raiheinäkasvustojen korkeus oli yhtä suuri kuin pelkän turvekasvualustankin.

Kasvun kontrollikasvualustana voidaan pitää ruokamultaa, jonka tuoresato oli $43 \mathrm{~g} / \mathrm{astia}$. Tämä vastaa hyvää 20,4 t/ha tuoresatoa. Vastaava kuiva-ainesato oli 2,94 t/ha (Kuva 4). Tämän lisäksi raiheinä kasvoi hyvin vain kompostoidussa Kemicond-lietteessä, joka oli katettu ruokamullalla. Tuoresato oli 49 $\mathrm{g}$ /astia. Ottaen huomioon pienempi astian poikkileikkaus, se vastasi $27,7 \mathrm{t} / \mathrm{ha}$ tuoresatoa. Vastaava kuivaainesato oli 3,36 t/ha. Ruokamullalla katetun kompostoidun Kemicond-lietteen tuoresato oli $36 \%$ parempi, mutta kuiva-ainesato vain $13 \%$ parempi kuin pelkän ruokamullan ollessa kasvualustana. Ruokamullalla katetun kompostoidun Kemicond-lietteen tuoresato oli erittäin merkitsevästi $(\mathrm{p}<0,001)$ korkeampi kuin ruokamullassa, mutta kuiva-ainesadot eivät enää eronneet toisistaan merkitsevästi. Kasvuston korkeudella mitattuna myös eräät muut käsittely kasvoivat hyvin raiheinää, mutta ne olivat ilmeisen kuihtuneita, koska sato jäi pieneksi (Kuva 4) ja niiden kuiva-ainepitoisuudet olivat suuremmat. Turvetta katteena sisältäneiden kasvualustojen kasvu kärsi turpeen matalasta $\mathrm{pH}$ :sta, ja pelkkää turvettakin sisältäneen kasvualustan kasvu oli vain 2 tuoregrammaa.

Kokeen lopussa raiheinän kasvu heikentyi jonkin verran kompostoimattomien lietteiden $40 \mathrm{~cm}$ lieriöissä, mikä todennäköisesti aiheutui siitä, että raiheinän juuristo ulottui tällöin $5 \mathrm{~cm}: n$ pintakerroksen alapuolella olevaan jätevesilietteeseen. Kasvu oli selvästi paras, kun 11 kk:ta kompostoidun Kemicond- 
lietteen päällä oli $5 \mathrm{~cm}: n$ ruokamultakerros. Tämä käsittely voitiin tehdä vain yhteen astiaan kyseisen lietteen liian pienen käytettävissä olevan erän takia, mutta on ilmeistä, että kompostoidulla Kemicondlietteelle ei ollut ruokamultakerroksen alapuolella ainakaan negatiivista vaikutusta raiheinän kasvuun. Kun kasvualustassa oli ruokamultakerroksen alla jotain muuta jätevesilietettä, tuottivat ne vain 6-14 g:n (600 $1300 \mathrm{~kg} / \mathrm{ha}$ ) kuiva-ainesadon astiaa kohti. Paksumpi ruokamultakerros lietteen päällä saattaisi tuottaa paremman sadon näillä lietteillä täytetyissä lieriöissä.

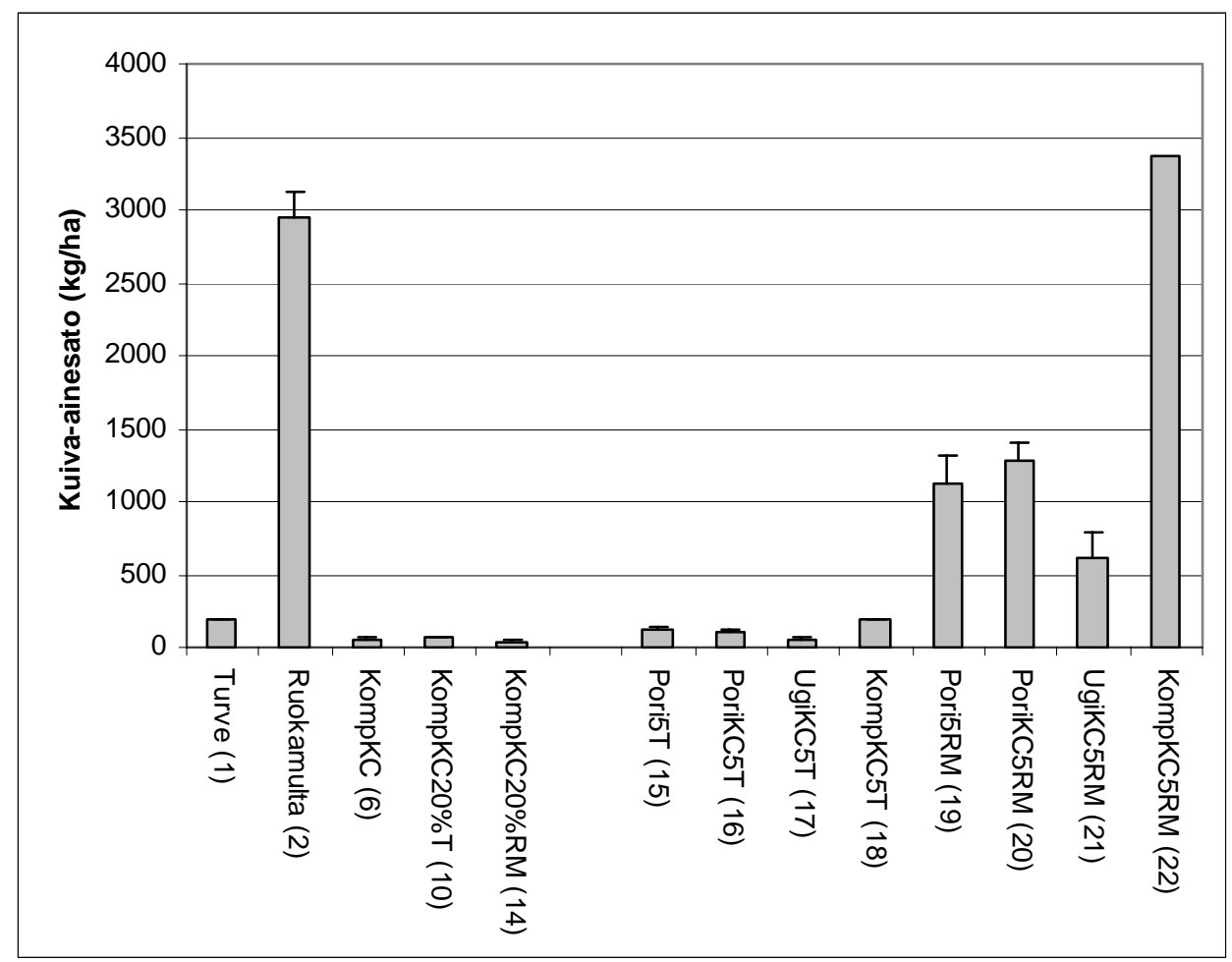

Kuva 4. Raiheinän kuiva-ainesato 4.10.2006. Virhepalkit ovat keskihajonnat kolmesta astiasta. Kompostoidusta Kemicond-lietteestä $40 \mathrm{~cm}: n$ lieriöissä oli vain yksi toisto, joten sen kuiva-ainesadon keskihajontaa ei voitu laskea.

\section{Johtopäätökset}

Kaikki lietteet olivat sellaisenaan liian väkeviä kasvualustaksi. Kompostoidussa Kemicond-lietteessä oli havaittavissa pientä taimettumista ja kasvua, mutta kasvu oli selvästi heikompaa kuin ruokamullassa. Kahdenkymmenen tilavuusprosentin tilavuusosuus ruokamultaa tai kasvuturvetta ei riittänyt laimentamaan lietettä kompostoitua Kemicond-lietettä lukuun ottamatta niin, että raiheinä olisi siinä taimettunut ja kasvanut. Viiden senttimetrin paksuinen ruokamulta tai turvekerros katteena lietteiden päällä edisti raiheinän kasvua, mutta vain kompostoitu Kemicond-liete katettuna ruokamullalla tuotti hyvän kasvun.

Jos kaatopaikan tai vastaavan maisemointiin käytetyn Kemicond-lietteen halutaan kasvavan vihreänä ruohoa, sitä on syytä ensin kompostoida noin vuosi, minkä jälkeen se voidaan kattaa ruokamullalla ja siihen voidaan kylvää jotain heinäkasvia. Kokeissa käytettiin yksivuotista raiheinää, mutta käytännön toiminnassa on tarkoituksenmukaisinta käyttää jotain monivuotista heinäkasvia, jotka kasvustoa ei tarvitse perustaa joka vuosi uudelleen. Monivuotisilla nurmikasveilla kasvutulosten voidaan olettaa olevan samanlaiset kuin yksivuotisella raiheinälläkin.

\section{Kirjallisuus}

CEN. 1999a. SFS-EN13037. Soil improvers and growing media - Determination of $\mathrm{pH}$.

CEN. 1999b. SFS-EN13038. Soil improvers and growing media - Determination of electrical conductivity Eduskunta. 2006. Lannoitevalmistelaki 539. Annettu Naantalissa 29. kesäkuuta 2006.

MMM. 2007. Maa- ja metsätalousministeriön asetus lannoitevalmisteista 12. Annettu 13. helmikuuta 2007.

MTT. 1986. Methods of soil and plant analysis. Jokioinen: Maatalouden tutkimuskeskus. 45 s. ISBN 951-729-285-6. 
VN. 2000. Valtioneuvoston asetus maataloudesta peräisin olevien nitraattien vesiin pääsyn rajoittamisesta 931 . Annettu Helsingissä 9. marraskuuta 2000.

VN. 2007. Valtioneuvoston asetus luonnonhaittakorvauksista ja maatalouden ympäristötuista vuosina 2007-2013 366. Annettu Helsingissa 4. huhtikuuta 2007.

Viljavuuspalvelu. 2000. Viljavuustutkimuksen tulkinta peltoviljelyssä. Mikkeli: Viljavuuspalvelu Oy. 31 s. VYL. 2004. Viherympäristöliiton suositukset kasvualustan ohjearvoiksi. 1 s. (http://www.vyl.fi) 